\title{
Cooking Characteristics, Eating Quality, and Preference of Some Rice Varieties Grown Experimentally in Puerto Rico ${ }^{1}$
}

\author{
J.R. Benero and M. A. González ${ }^{2}$
}

ABSTRACT

A 10-12 member tasting panel appraised cooked samples of 26 rice varieties as to appearance, cohesion, tenderness, and flavor; and judged 25 of those varieties for eating quality using a $+2,-2$ (acceptable - not acceptable) scale. All samples had good cooking characteristics. The eating quality of IR-8 and Chontalpa 59 was questionable. An additional test showed preference for Sunbonnet and Starbonnet. Bluebelle was very close to the significant level of preference. The commercial sample came close to a significant level of preference over Chontalpa 59.

\section{INTRODUCTION}

Efforts are being made to establish a rice industry in Puerto Rico. Several varieties have been imported and field tested. Chemical and physical measurements give an indication of the cooking characteristics and eating quality of rice varieties (3), but it is the cooking and tasting alone which provide most reliable information on characteristics and quality. Cooking the rice samples by a standardized procedure and submitting them to a sensory evaluation by a trained panel is a sound procedure to ascertain cooking characteristics and eating quality. Batcher et al. (1) described a standard cooking procedure for the evaluation of the cooking and eating quality of rice. Batcher et al. (2) also reported on the cooking quality of 26 rice varieties, four of which were included in this study. Quality evaluation of foreign and domestic rices was done by Simpson et al. (5), but they did not name the varieties studied.

\section{MATERIALS AND METHODS}

Single rice samples from experimental plots during the years 1973 and 1974 were milled after they were dried to 12 to $14 \%$ moisture. Milling was done under controlled conditions, using the standard equipment for rice milling tests specified by the USDA (6). The samples were graded according to U.S. standards, placed in well protected sample bottles, and stored in a dry cool place until used. Only US No. 1 grade samples were used for the evaluation studies.

${ }^{1}$ Manuscript submitted to Editorial Board September 29, 1977.

${ }^{2}$ Associate Chemist and Technical Director, respectively, Food Technology Laboratory, Agricultural Experiment Station, Mayagüez Campus, University of Puerto Rico, Río Piedras, P.R. 
Name

Date

Product

Palatability Characteristics of Cooked Rice

Sample No.

\begin{tabular}{|c|c|c|c|c|}
\hline Scale & Appearance & Cohesion & Tenderness & Flavor \\
\hline 5 & $\begin{array}{l}\text { Whole smooth } \\
\text { grains }\end{array}$ & Well separated & Hard centers & No off flavors \\
\hline 4 & Fuzzy edges & Partially separated & Firm and chewy & $\begin{array}{l}\text { Perceptible off fla- } \\
\text { vors }\end{array}$ \\
\hline 3 & Sloughing & $\begin{array}{l}\text { Sticky or slightly } \\
\text { clumped }\end{array}$ & Tender and firm & $\begin{array}{l}\text { Slightly strong off } \\
\text { flavors }\end{array}$ \\
\hline 2 & $\begin{array}{l}\text { Indistinct broken } \\
\text { grains }\end{array}$ & Very sticky, clumped & Soft & $\begin{array}{l}\text { Moderately strong } \\
\text { off flavors }\end{array}$ \\
\hline 1 & Disintegrated & Pasty & Mushy & $\begin{array}{l}\text { Very strong off fla- } \\
\text { vors }\end{array}$ \\
\hline
\end{tabular}

FIG. 1. - Tasting ballot used for the evaluation of cooking characteristics.

TABLE 1. - Appearance of cooked samples of 26 rice varieties

\begin{tabular}{lcl}
\hline \multicolumn{1}{c}{ Variety } & Score (average) & \multicolumn{1}{c}{ Description } \\
\hline Sinaloa A68-1C & 4.8 & Whole smooth grains \\
Sinaloa A68-8C & 4.8 & Whole smooth grains \\
Chontalpa 437 & 4.7 & Whole smooth grains \\
Vista 96-28-2 & 4.6 & Whole smooth grains \\
Colusa & 4.6 & Whole smooth grains \\
Caloro & 4.5 & Whole smooth grains \\
Chontalpa 59 & 4.5 & Whole smooth grains \\
Juma 13 & 4.4 & Grains with fuzzy edges \\
IR-8 & 4.4 & Grains with fuzzy edges \\
Girona & 4.4 & Grains with fuzzy edges \\
Brazos & 4.4 & Grains with fuzzy edges \\
Chontalpa 16 & 4.4 & Grains with fuzzy edges \\
Sinaloa A68-19C & 4.3 & Grains with fuzzy edges \\
Balilla & 4.3 & Grains with fuzzy edges \\
Venus & 4.2 & Grains with fuzzy edges \\
Dosel & 4.2 & Grains with fuzzy edges \\
Bluebelle & 4.2 & Grains with fuzzy edges \\
Bahía & 4.2 & Grains with fuzzy edges \\
Starbonnet & 4.2 & Grains with fuzzy edges \\
Sunbonnet & 4.2 & Grains with fuzzy edges \\
Juma 18 & 4.2 & Grains with fuzzy edges \\
Amposta & 4.1 & Grains with fuzzy edges \\
Galaxia & 4.1 & Grains with fuzzy edges \\
Juma 1 & 4.1 & Grains with fuzzy edges \\
Bluebonnet 50 & 4.1 & Grains with fuzzy edges \\
Nano $\times$ Sollana & 4.0 & Grains with fuzzy edges \\
\hline
\end{tabular}


The samples were cooked by the oven method (1). To $400 \mathrm{ml}$ of boiling distilled water in a covered porcelain bowl, $4 \mathrm{~g}$ of table salt and $200 \mathrm{~g}$ of the rice sample were added. The bowl was placed immediately in a preheated oven at $350^{\circ} \mathrm{F}$ for $28 \mathrm{~min}$, after which the lid was removed and the sample cooked for 5 additional min. This procedure was followed with all samples irrespective of grain size.

To determine the cooking characteristics, the cooked samples were judged by 10 to 12 members of a trained tasting panel who were asked to score their judgments on a ballot similar to the one used by Simpson

TABLE 2. - Cohesion of cooked samples of 26 rice varieties

\begin{tabular}{lcl}
\hline \multicolumn{1}{c}{ Variety } & Score (average) & \multicolumn{1}{c}{ Description } \\
\hline Chontalpa 59 & 4.9 & Well separated grains \\
Nano $\times$ Sollana & 4.6 & Well separated grains \\
Chontalpa 437 & 4.4 & Partially separated \\
IR-8 & 4.3 & Partially separated \\
Sinaloa A68-8C & 4.3 & Partially separated \\
Juma 18 & 4.1 & Partially separated \\
Starbonnet & 4.0 & Partially separated \\
Venus & 3.9 & Partially separated \\
Sinaloa A68-1C & 3.8 & Partially separated \\
Bluebonnet-50 & 3.8 & Partially separated \\
Bluebelle & 3.8 & Partially separated \\
Chontalpa 16 & 3.8 & Partially separated \\
Sinaloa A68-19C & 3.8 & Partially separated \\
Vista 96-28-2 & 3.8 & Partially separated \\
Juma 13 & 3.7 & Partially separated \\
Sunbonnet & 3.6 & Partially separated \\
Galaxia & 3.6 & Partially separated \\
Girona & 3.6 & Partially separated \\
Bahía & 3.4 & Sticky or slightly clumped \\
Brazos & 3.3 & Sticky or slightly clumped \\
Dosel & 3.2 & Sticky or slightly clumped \\
Colusa & 3.2 & Sticky or slightly clumped \\
Balilla & 3.1 & Sticky or slightly clumped \\
Caloro & 3.0 & Sticky or slightly clumped \\
Juma 1 & 2.9 & Sticky or slightly clumped \\
Amposta & 2.9 & Sticky or slightly clumped \\
\hline & &
\end{tabular}

et al. (5), with the scale reduced to 5 points (fig. 1). Only one sample was presented at each tasting session.

To ascertain the eating quality, the samples were evaluated by the same trained panel using Kramer's +2, -2 (acceptable-not acceptable) scale (4). All samples were cooked as described above with the addition of $25 \mathrm{ml}$ of vegetable oil to the boiling water. Again only one sample was appraised at each tasting session.

To compare an experimental sample with a commercial sample, both 
samples were cooked simultaneously by the method previously described, including the addition of vegetable oil. They were presented, coded, simultaneously to the panelists. Tasters were asked to consider the overall characteristics and to indicate which one they preferred. The test was replicated two or three times. The results were analyzed for significance by the chi-square test.

TABLE 3. - Tenderness of 26 rice varietes after cooking

\begin{tabular}{lcl}
\hline \multicolumn{1}{c}{ Variety } & Score (average) & \multicolumn{1}{c}{ Description } \\
\hline Juma 18 & 4.8 & Hard centers \\
Galaxia & 4.4 & Firm and chewy \\
Chontalpa 59 & 4.4 & Firm and chewy \\
Nano $\times$ Sollana & 4.2 & Firm and chewy \\
Sunbonnet & 4.2 & Firm and chewy \\
Chontalpa 437 & 4.0 & Firm and chewy \\
Bahía & 3.9 & Firm and chewy \\
Bluebelle & 3.9 & Firm and chewy \\
Sinaloa A68-19C & 3.9 & Firm and chewy \\
Starbonnet & 3.9 & Firm and chewy \\
Colusa & 3.9 & Firm and chewy \\
IR-8 & 3.9 & Firm and chewy \\
Girona & 3.9 & Firm and chewy \\
Brazos & 3.9 & Firm and chewy \\
Chontalpa 16 & 3.8 & Firm and chewy \\
Venus & 3.8 & Firm and chewy \\
Vista 96-28-2 & 3.6 & Firm and chewy \\
Balilla & 3.6 & Firm and chewy \\
Sinaloa A68-8C & 3.6 & Firm and chewy \\
Juma 1 & 3.5 & Between firm and chewy and \\
Bluebonnet 50 & 3.5 & tender and firm \\
Dosel & 3.3 & Between firm and chewy and \\
Juma 13 & 3.3 & Tender and firm \\
Sinaloa A68-1C & 3.3 & Tender and firm \\
Amposta & 2.5 & Tender and firm \\
Caloro & 2.3 & Between tender and firm and \\
& & Soft \\
\hline
\end{tabular}

\section{RESULTS AND DISCUSSION}

Four cooking characteristics were evaluated in this study: appearance, cohesion, tenderness, and flavor. The scores and descriptions of the characteristics of each variety are presented in tables $1,2,3$, and 4 , respectively.

Table 1 gives the panel score and descriptive terms for appearance of the 26 varieties. All samples had good appearance. The lowest score (4.0) corresponds to grains with fuzzy edges. In judging appearance the 
tasters were asked to consider only the physical condition of the grains, disregarding color, since only white or slightly creamy samples were submitted for evaluation.

As indicated in table 2, Chontalpa 59 (long-grain) and Nano $\times$ Sollana (medium-grain) varieties cooked with well-separated grains. Juma I, a long-grain variety cooked with sticky or slightly clumped grains. None of the cooked samples was found to be very clumped or pasty. The scores for Bluebonnet 50, Sunbonnet, Caloro, and Colusa

TABLE 4. - Flavor of cooked samples of 26 rice varieties

\begin{tabular}{lcl}
\hline \multicolumn{1}{c}{ Variety } & Score (average) & \multicolumn{1}{c}{ Description } \\
\hline Bluebonnet 50 & 5.0 & No off flavors \\
Balilla & 5.0 & No off flavors \\
Starbonnet & 5.0 & No off flavors \\
Chontalpa 437 & 5.0 & No off flavors \\
Brazos & 4.9 & No off flavors \\
Chontalpa 16 & 4.9 & No off flavors \\
Chontalpa 59 & 4.9 & No off flavors \\
Juma 13 & 4.9 & No off flavors \\
Sinaloa A68-8C & 4.9 & No off flavors \\
Galaxia & 4.9 & No off flavors \\
Girona & 4.9 & No off flavors \\
Caloro & 4.8 & No off flavors \\
Venus & 4.8 & No off flavors \\
IR-8 & 4.8 & No off flavors \\
Nano $\times$ Sollana & 4.8 & No off flavors \\
Sunbonnet & 4.7 & No off flavors \\
Sinaloa A68-1C & 4.7 & No off flavors \\
Colusa & 4.7 & No off flavors \\
Sinaloa A68-19C & 4.7 & No off flavors \\
Dosel & 4.7 & No off flavors \\
Juma 18 & 4.6 & No off flavors \\
Juma 1 & 4.6 & No off flavors \\
Amposta & 4.5 & No off flavors \\
Bahía & 4.5 & No off flavors \\
Bluebelle & 4.5 & Perceptible off flavors \\
Vista 96-28-2 & 4.1 & \\
\hline
\end{tabular}

were similar to the ones reported by Batcher et al. (2) for these varieties. The general trend, where cooked long-grain varieties are more loose and flaky than short- or medium-grain ones, was observed.

Table 3 includes the score and corresponding descriptive tests for tenderness.

The great majority of the samples were found to be firm and chewy, indicating that they were slightly under the optimum doneness. Juma18 had hard centers, while Caloro was soft; none was pasty. A shift toward the upper end of the scale is observed. This may be due to the 
volume of water used. Batcher et al. used $250 \mathrm{ml}$ of water per $100 \mathrm{~g}$ of long-grain rice and $200 \mathrm{ml}$ per $100 \mathrm{~g}$ of medium or short-grain varieties. In this test all samples were cooked in $200 \mathrm{ml}$ of water per $100 \mathrm{~g}$ of rice, irrespective of grain size.

All samples, as indicated in table 4, were found to have no off flavors, with the exception of Vista 96-28-2, which had a score of 4.1, denoting perceptible off flavors. The judges described the off flavor as a stale or strawlike flavor. Since these samples had been stored for about two years, off flavor development could have taken place. Possibly,

TABLE 5. -Eating quality of 25 rice varieties

\begin{tabular}{lcl}
\hline \multicolumn{1}{c}{ Variety } & Score (average) & Description \\
\hline Galaxia & 1.4 & Acceptable \\
Sunbonnet & 1.3 & Acceptable \\
Starbonnet & 1.3 & Acceptable \\
Venus & 1.2 & Acceptable \\
Chontalpa 437 & 1.2 & Acceptable \\
Bluebelle & 1.1 & Acceptable \\
Bluebonnet 50 & 1.1 & Acceptable \\
Juma 1 & 1.1 & Acceptable \\
Sinaloa A68-1C & 1.0 & Acceptable \\
Sinaloa A68-19C & 1.0 & Acceptable \\
Juma 13 & 1.0 & Acceptable \\
Sinaloa A68-8C & 1.0 & Acceptable \\
Dosel & 1.0 & Acceptable \\
Bahía & 1.0 & Acceptable \\
Amposta & 1.0 & Acceptable \\
Brazos & 1.0 & Acceptable \\
Nano $\times$ Sollana & 1.0 & Acceptable \\
Colusa & 1.0 & Acceptable \\
Chontalpa 16 & .9 & Acceptable \\
Vista 96-28-2 & .9 & Acceptable \\
Girona & .8 & Acceptable \\
Juma 18 & .8 & Acceptable \\
Caloro & .6 & Acceptable \\
IR-8 & .4 & Questionable \\
Chontalpa 59 & .3 & Questionable \\
\hline
\end{tabular}

Vista 96-28-2 had no off flavor when fresh. All samples showed good keeping quality.

The results of the eating quality tests of 25 rice varieties are presented in table 5. The scores range was from 0.3 to 1.4. Only two samples, IR-8 and Chontalpa 59, were rated questionable in quality; all other samples were found acceptable. Why these samples scored lower than the others is not known. Rice samples were cooked with vegetable oil and salt because Puerto Ricans boil rice with water to which lard, vegetable oil, or other shortening is added. Hence, for rice to be judged 
for eating quality for the Puerto Rican market, samples were cooked according to local custom.

The same 25 experimental samples that were appraised for eating quality were compared individually for preference with a commercial rice sample (Colusa variety) of a trade brand known to have very good consumer acceptance. Sunbonnet $\left(\chi^{2}=9.0909\right)$ and Starbonnet $\left(\chi^{2}=\right.$ $7.3142)$ were highly prefered. Bluebelle $\left(\chi^{2}=3.3684\right)$ came very close to a significant level of preference. The commercial sample $\left(\chi^{2}=3.6818\right)$ approached the significant level of preference over Chontalpa 59. No significant preference could be established between the rest of the samples and the commercial one.

\section{RESUMEN}

Un panel de 10 a 12 catadores debidamente entrenados evaluó muestras de 26 variedades de arroz cocidas en horno por un método estándar, con respecto a las siguientes características: apariencia, cohesión, blandura y sabor. El mismo panel examinó 25 variedades para determinar la calidad al degustarlas, usando una escala $(+2,-2)$ (aceptable-no aceptable). Se realizaron pruebas de preferencia entre 25 muestras experimentales y una muestra comercial de una marca de reconocida aceptación por los consumidores. Todas las muestras tenían buenas propiedades de cocción. La calidad de las variedades IR-8 y Chontalpa 59 resultó ser dudosa. La preferencia por las variedades Sunbonnet y Starbonnet excedió a la comercial en forma altamente siginificativa. Bluebelle estuvo muy cerca de ser preferida significativamente y la variedad comercial estuvo muy cerca de ser significativamente preferida a la variedad Chontalpa 59.

\section{LITERATURE CITED}

1. Batcher, O. M., Helmintoller, K. F., and Dawson, E. H., 1956. Development and application of methods for evaluating cooking and eating quality of rice, Rice J. 59(13): 4-8, 32 .

2. Batcher, O. M., Deary, P. A., and Dawson, E. H., 1957. Cooking quality of 26 varieties of milled white rice, Cereal Chem. 34(7): 277-85.

3. Juliano, O. B., 1977. Recent developments in rice research, Cereal Food World, 22(7): 284-7.

4. Kramer, A., and Ditman, S., 1956. Simplified variable taste panel method for detecting flavor changes in vegetables treated with pesticides, Food Technol. 10: $155-9$.

5. Simpson, J. E., Adair, C. R., Kohler, G. O., Dawson, E. H., Deobald, H. J., Kester, E. B., Hogan, J. T., Batcher, O. M., and Halick, J. V., 1965. Quality evaluation studies of foreign and domestic rices, Tech. Bull. No. 1331 ARS, USDA.

6. USDA Rice Inspection Manual GR: Instruction No. 918-2 June 10, 1968. 